\title{
Epidemiology and risk factors of infective endocarditis in a tertiary hospital in China from 2007 to 2016
}

\author{
Zhenzhu $\mathrm{Wu}^{1,2+}{ }^{+} \mathrm{Yi}_{\mathrm{C}} \mathrm{Chen}^{1 \dagger}$, Tingting Xiao ${ }^{1}$, Tianshui Niu${ }^{1}$, Qingyi Shi ${ }^{1}$ and Yonghong Xiao ${ }^{1 *}$
}

\begin{abstract}
Background: To explore the trends in epidemiology and the risk factors related to the prognosis of infective endocarditis in a tertiary hospital over the past ten years.

Methods: A retrospective cohort study was performed. A total of 407 consecutive patients who were admitted with infective endocarditis were included. The clinical characteristics and the risk factors related to the prognosis of infective endocarditis during this period were analyzed.

Results: A total of 407 patients with infective endocarditis were included, the average age was $48 \pm 16$ years old with an increasing trend and in-hospital mortality rate was $10.6 \%$ and one-year mortality rate was $11.3 \%$. Among patients with underlying heart disease, congenital heart disease was the most common (25.8\%), followed by rheumatic heart disease $(17.0 \%)$ which showed a decreased trend during this period $(\mathrm{P}<0.001)$. There were 222(54.5\%) patients with positive blood cultures results and Streptococci (24.6\%) was the main pathogens with an increasing trend. There were 403 patients (99\%) with surgical indications, but only 235 patients (57.7\%) received surgical treatment. Hemodialysis $(P=0.041, \mathrm{OR}=4.697,95 \% \mathrm{Cl} 1.068-20.665)$, pulmonary hypertension $(P=0.001, O R=5.308,95 \% \mathrm{Cl} 2.034-13.852)$, Pitt score $\geq 4(P<0.001, \mathrm{OR}=28.594,95 \%$ $\mathrm{Cl} 5.561-148.173)$ and vegetation length $>30 \mathrm{~mm}(\mathrm{P}=0.011, \mathrm{OR}=13.754,95 \% \mathrm{Cl} 1.832-103.250)$ were independent risk factors for in-hospital mortality.

Conclusions: There were no significant changes in the overall incidence of infective endocarditis, but the clinical features of infective endocarditis had slightly changed during the past ten years. Streptococci infective endocarditis was still the predominant. Patients with hemodialysis, pulmonary hypertension, Pitt score $\geq 4$ and vegetation length>30 $\mathrm{mm}$ had an worse in-hospital outcome.
\end{abstract}

Keywords: Infective endocarditis, Epidemiology, Risk factors, Mortality

\footnotetext{
* Correspondence: xiaoyonghong@zju.edu.cn

${ }^{\dagger}$ Zhenzhu Wu and Yi Chen contributed equally to this work.

'State Key Laboratory for Diagnosis and Treatment of Infectious Diseases,

National Clinical Research Center for Infectious Diseases,Collaborative

Innovation Center for Diagnosis and Treatment of Infectious Diseases, the

First Affiliated Hospital, College of Medicine, Zhejiang University, 79

Qingchun Road, Hangzhou, Zhejiang Province, China

Full list of author information is available at the end of the article
}

(C) The Author(s). 2020 Open Access This article is licensed under a Creative Commons Attribution 4.0 International License, which permits use, sharing, adaptation, distribution and reproduction in any medium or format, as long as you give appropriate credit to the original author(s) and the source, provide a link to the Creative Commons licence, and indicate if changes were made. The images or other third party material in this article are included in the article's Creative Commons licence, unless indicated otherwise in a credit line to the material. If material is not included in the article's Creative Commons licence and your intended use is not permitted by statutory regulation or exceeds the permitted use, you will need to obtain permission directly from the copyright holder. To view a copy of this licence, visit http://creativecommons.org/licenses/by/4.0/ The Creative Commons Public Domain Dedication waiver (http://creativecommons.org/publicdomain/zero/1.0/) applies to the data made available in this article, unless otherwise stated in a credit line to the data. 


\section{Background}

Infective endocarditis (IE) is an infectious disease involving the heart valve or endocardium caused by causative microorganisms. It is a severe disease with high morbidity and mortality [1]. Serious complications such as heart failure and cerebral embolism are common. In developed countries, the annual incidence is between 3 and 9 patients per 100,000 persons with a slight increase between 1970 and 2013 [1, 2]. Although the improvement of prevention, the progress of antibiotic therapy, the development of imaging technology and the intervention with surgery, the mortality is still up to $15-30 \%$ [3]. Over the past two decades, with the increase in life expectancy, the increased use of cardiac implant devices, and the frequency in invasive procedures, the epidemiology of IE in developed countries such as the Europe and the United States has changed significantly: older patients with IE gradually increased, prosthetic valve endocarditis (PVE) and cardiac device-related endocarditis increased, and Staphylococci has become the most predominated pathogen [4].

However, studies from developing countries such as Turkey showed a different epidemiological character [5]. In their study, although Staphylococcal IE was increasing, Streptococci was still the most predominant pathogen; rheumatic heart disease (RHD) and congenital heart disease (CHD) were still the most common underlying heart diseases, and the number of patients undergoing surgical treatment was increasing $[5,6]$. In this study, we analyzed the changes in clinical features of IE over the past 10 years in a tertiary teaching hospital to explore the epidemiological trend and the risk factors related to the prognosis of IE.

\section{Methods}

\section{Patients}

A retrospective, consecutive case-series analysis was organized and performed in the First Affiliated Hospital of Zhejiang University, Hangzhou, China. Patients with a clinical diagnosis of IE from January 1, 2007 to December 31, 2016 were reviewed. The Modified Duke criteria [7] was used to evaluate patients reviewed. Patients who were admitted to the hospital more than one time for the same pathogen during the study period were considered as one case.

\section{Clinical parameters and study design}

The data were retrieved from the Electronic Medical Record. The data included in the analysis were patient demographic information, underlying heart diseases, comorbidities, clinical manifestations, complications, causative microorganisms, echocardiographic demonstrations, treatments and outcomes. The following data analysis strategies were conducted: (1) The changing trend of clinical characteristics in IE was analyzed with every two-year time period; (2) To explore the prognostic risk factors, a comparison between the survival group and the death group was conducted.

\section{Definition}

Infective endocarditis was categorized based on disease types according to the 2015 European Society of Cardiology (ESC) guidelines for the management of infective endocarditis as native-valve endocarditis, prostheticvalve endocarditis, and cardiac device-related endocarditis [7].

Embolic events were diagnosed by imaging techniques including cerebral embolism and non-central nervous system embolism.

Heart failure was diagnosed according to the Framingham criteria [8]: major criteria were physician assessment of neck-vein distension, rales, S3 gallop, venous pressure $>16 \mathrm{~cm}$ of water, hepatojugular reflux, and weight loss of $4.5 \mathrm{~kg}$ in 5 days due to diuretic therapy, and minor criteria were ankle edema, night cough, dyspnea on exertion, hepatomegaly, tachycardia and weight loss. "Definite Heart failure" was defined as having at least two major criteria, or one major criterion and two minor criteria.

Renal insufficiency was defined as endogenous creatinine clearance rate $(\mathrm{Ccr})<60 \mathrm{~mL} / \mathrm{min} / 1.73 \mathrm{~m} 2$.

Pulmonary hypertension was defined by a resting mean pulmonary artery pressure $\geq 25 \mathrm{mmHg}$, pulmonary artery wedge pressure $<15 \mathrm{mmHg}$, and pulmonary vascular resistance $>3$ Wood Units by echocardiography.

Surgical indications were based on the 2015 ESC guidelines for the management of infective endocarditis [7] including: heart failure, uncontrolled infection, vegetation $>10 \mathrm{~mm}$ or evidence of vegetation embolic event.

Previous antibiotic use referred to the use of antibiotics for $>72 \mathrm{~h}$ at any point 2 weeks prior to IE diagnosis.

Transthoracic echocardiogram (TTE) was performed routinely in all patients. Transesophageal echocardiogram (TEE) was used to detect cases with negative TTE results. Blood culture was performed in all the patients with aerobic, anaerobic and fungal blood cultures, but blood culture for the HACEK group (Haemophilus spp, Aggregatibacter spp, Cardiobaterium hominis, Eikenella corrodens, and Kingella kingae) and anti-legionella, mycoplasma and bartonella anti-body tests as well as PCR test were not performed.

The main outcome was in-hospital all-cause mortality and one-year all-cause mortality. The one-year follow-up data were collected from the patients' latest visits to the hospital.

\section{Statistical analysis}

The trends in clinical characteristics was analyzed using the log-linear Poisson regression model. Univariate analysis was 
performed using the Pearson's $\chi^{2}$ test or Fisher's exact tests as appropriate for categorical variables and the independent Student's t-test or the Rank sum test as appropriate for continuous variables. Categorical variables were expressed as frequencies and percentages of the specified group and continuous variables were reported as averages with standard deviations or medians and interquartile ranges. After univariate analysis, variables with $P<0.05$ were included in multivariate analysis to identify predictors for in-hospital mortality among IE patients. Odds ratios (OR) with 95\% confidence interval $(\mathrm{CI})$ were calculated in logistic regression. All tests were 2 -tailed, and $P<0.05$ was considered statistically significant. All analyses were performed using SPSS version 23 statistical software.

\section{Results}

\section{Patient enrollment}

In the study, there were 409 patients with IE and 2 patients whose blood culture results were unreachable were excluded. A total of 407 IE patients were included. There were 378 (92.8\%) patients taking part in the study completed the one-year follow up after infective endocarditis diagnosis. There were 43 patients (10.6\%) died during hospitalization and 46 patients (11.3\%) died in the one-year follow-up.

\section{The clinical characteristics of patient with IE}

Among the 407 patients, 262 patients were male $(64.4 \%)$. The average age was $48 \pm 16$ years old with an increasing trend during this period $(P=0.001)$ (Table 1$)$. The annual incidence of IE were between 0.33 and 0.72 patients per 1000 admissions and the incidence was stable over this period (Fig. 1).

There were 186 patients (45.7\%) without underlying heart disease and the proportion increased over this time $(P=0.044)$. CHD was the most common underlying heart disease, accounting for $25.8 \%$ of all patients, and the proportion of RHD decreased yearly during this period $(P<0.001)$. Patients with degenerative valvular disease (DVD) accounted for $3.2 \%$ with a growing trend $(P=0.001)$. Native valve IE was still the most dominant, accounting for $90.9 \%$ and the proportion increased over this time $(P=0.002)$. There were 37 patients $(9.1 \%)$ with diabetes mellitus and 18 patients (4.4\%) with hepatitis B virus infection. Except for hypertension with a significant increase in the proportion $(P=0.005)$, the proportion of other comorbidities did not change significantly. There were 215 patients (52.8\%) with heart failure and 74 patients $(18.2 \%)$ with cerebral embolism. The proportion of cerebral embolism was significantly increased during this period $(P=0.001)$.

TEE was performed on 52 patients $(12.8 \%)$ and $30 \mathrm{pa}-$ tients $(7.4 \%)$ were diagnosed after TEE. The detection rate of vegetation was $86.0 \%$ with a significant growth trend $(P<0.001)$. There were 72 patients $(17.8 \%)$ with valve perforation and 30 patients $(7.4 \%)$ with perivalvular abscess. Left-side IE was the most common with 356 patients (87.5\%). A single valve being affected was more common, with 295 patients (72.5\%), among which the mitral valve was affected in 134 patients $(32.9 \%)$ and the aortic valve was affected in 143 patients (35.1\%).

Blood cultures were performed in all patients with IE. There were 222 (54.5\%) positive blood cultures results. Patients with negative blood culture were diagnosed as definite IE by the following criteria: 173 patients had positive echocardiographic findings plus three minor criterias, and 12 patients were identified by positive histopathological findings. Streptococci was the main pathogen, accounting for $24.6 \%$ with an increasing trend, followed by Staphylococci, accounting for 19.7\%. There were 40 patients (9.8\%) of Staphylococcus aureus IE, including 26 patients (6.4\%) of Methicillin-resistant Staphylococcus aureus (MRSA) IE. Other pathogens identified by blood cultures were: Gram-negative bacilli in 28, Enterococci in 5, Corynebacterium in 3 and Kocuria roseus in 1. Polymicrobial infection was identified in 5 patients.

There were 403 patients (99.0\%) with surgical indications but only 235 patients (57.7\%) with surgical treatment. Among those with surgical indications, 215 patients $(52.8 \%)$ with heart failure, 125 patients (30.7\%) with embolic events, 260 patients $(63.9 \%)$ with vegetation $>10 \mathrm{~mm}$, and 43 patients $(10.6 \%)$ with uncontrolled infection. There were 68 patients $(16.7 \%)$ with one surgical indication and 335 patients $(82.7 \%)$ with more than one surgical indications.

\section{The risk factors for in-hospital mortality}

Univariate analysis found that age, previous heart valve surgery, hemodialysis, hypertension, heart failure, cerebral embolism, cerebral hemorrhage, arrhythmia, hepatic insufficiency, renal insufficiency, pulmonary hypertension, vegetation length $>30 \mathrm{~mm}$, prosthetic valve or pacemaker valve IE, Staphylococcus aureus infection, Pitt score $\geq 4$,surgical treatment were related to the inhospital mortality (Table 2). Multifactor analysis found that hemodialysis $(P=0.041$, OR $=4.697,95 \%$ CI 1.068 20.665), pulmonary hypertension $(P=0.001$, OR $=5.308$, 95\% CI 2.034-13.852), Pitt score $\geq 4 \quad(P<0.001$, OR $=$ 28.594, 95\% CI 5.561-148.173) and vegetation length $>30 \mathrm{~mm} \quad(P=0.011$, OR $=13.754,95 \%$ CI 1.832 103.250) were independent risk factors for in-hospital mortality (Table 3).

\section{Discussion}

Over the past decades, the epidemiology of IE has changed due to changes in demographic characteristics and risk factors. Researches from developed countries have 
Table 1 The clinical characteristics of infective endocarditis and changing trends by years from 2007 to 2016

\begin{tabular}{|c|c|c|c|c|c|c|c|}
\hline Variable, n(\%) & $\begin{array}{l}\text { Total } \\
n=407\end{array}$ & $\begin{array}{l}2007-2008 \\
n=62\end{array}$ & $\begin{array}{l}2009-2010 \\
n=63\end{array}$ & $\begin{array}{l}2011-2012 \\
n=78\end{array}$ & $\begin{array}{l}2013-2014 \\
n=89\end{array}$ & $\begin{array}{l}2015-2016 \\
n=115\end{array}$ & $P$ value \\
\hline Male & $262(64.4)$ & $40(64.5)$ & $42(66.7)$ & $53(67.9)$ & $56(62.9)$ & $71(61.7)$ & .513 \\
\hline Age,mean $\pm S D$ & $48 \pm 16$ & $45 \pm 15$ & $42 \pm 15$ & $47 \pm 16$ & $50 \pm 16$ & $52 \pm 16$ & .001 \\
\hline \multicolumn{8}{|l|}{ Comorbidities } \\
\hline Hypertension & $82(20.1)$ & $9(14.5)$ & $9(14.3)$ & $11(14.1)$ & $20(22.5)$ & $33(28.7)$ & .005 \\
\hline Diabetes mellitus & $37(9.1)$ & $3(4.8)$ & $5(7.9)$ & $6(7.7)$ & $8(9.0)$ & $15(13.0)$ & .078 \\
\hline Hepatitis B virus infection & $18(4.4)$ & $1(1.6)$ & $2(3.2)$ & $5(6.4)$ & $6(6.7)$ & $4(3.5)$ & .501 \\
\hline Chronic organ disease & $23(5.7)$ & $3(4.8)$ & $3(4.8)$ & $2(2.6)$ & $6(6.7)$ & $9(7.8)$ & .260 \\
\hline Cancer & $12(2.9)$ & $2(3.2)$ & $2(3.2)$ & $4(5.1)$ & $2(2.2)$ & $2(1.7)$ & .474 \\
\hline No-underlying heart disease & $186(45.7)$ & $18(29.0)$ & $29(46.0)$ & $42(53.8)$ & $40(44.9)$ & $57(49.6)$ & .044 \\
\hline Underlying heart disease & $221(54.3)$ & $44(71.0)$ & $34(54.0)$ & $36(46.2)$ & $49(55.1)$ & $58(50.4)$ & .044 \\
\hline Congenital heart disease & $105(25.8)$ & $17(27.4)$ & $16(25.4)$ & $18(23.1)$ & $26(29.2)$ & $28(24.3)$ & .870 \\
\hline Rheumatic heart disease & $69(17.0)$ & $22(35.5)$ & $14(22.2)$ & $12(15.4)$ & $6(6.7)$ & $15(13.0)$ & $<.001$ \\
\hline Previous cardiac surgery & $44(10.8)$ & $11(17.7)$ & $6(9.5)$ & $6(7.7)$ & $15(16.9)$ & $6(5.2)$ & .086 \\
\hline Degenerative heart disease & $13(3.2)$ & 0 & 0 & $2(2.6)$ & $2(2.2)$ & $9(7.8)$ & .001 \\
\hline Hospital stay, mean \pm SD & $25 \pm 22$ & $31 \pm 31$ & $32 \pm 25$ & $23 \pm 17$ & $23 \pm 24$ & $21 \pm 15$ & .001 \\
\hline $\begin{array}{l}\text { Duration of Symptoms before echocardiography median (IQR), } \\
\text { days }\end{array}$ & $13(4-35)$ & $17(7-48)$ & $14(6-30)$ & $15(4-40)$ & $9(3-50)$ & $15(4-31)$ & .542 \\
\hline Duration of symptoms before diagnosis, median (IQR), days & $\begin{array}{l}25(12- \\
62)\end{array}$ & $26(12-68)$ & $24(9-42)$ & $25(14-62)$ & $28(10-75)$ & $26(13-62)$ & .434 \\
\hline Previous antibiotic use & $321(81.7)$ & $48(81.4)$ & $58(92.1)$ & $65(90.3)$ & $76(85.4)$ & $74(67.3)$ & .001 \\
\hline Intravenous drug abuse & $3(0.7)$ & $1(1.6)$ & $1(1.6)$ & 0 & 0 & $1(0.9)$ & .556 \\
\hline \multicolumn{8}{|l|}{ Symptoms and signs } \\
\hline Fever & $365(89.7)$ & $57(91.9)$ & $57(90.5)$ & $70(89.7)$ & $83(93.3)$ & $98(85.2)$ & .233 \\
\hline Anemia & $222(54.5)$ & $38(61.3)$ & $43(68.3)$ & $43(55.1)$ & $58(65.2)$ & $40(38.4)$ & $<.001$ \\
\hline Osler nodule & $7(1.7)$ & $2(3.2)$ & 0 & $3(3.8)$ & $2(2.2)$ & 0 & .288 \\
\hline Janeway lesions or nailbed bleeding & $4(0.9)$ & $1(1.6)$ & $3(4.8)$ & 0 & 0 & 0 & .060 \\
\hline TEE & $52(12.8)$ & $3(4.8)$ & $4(6.3)$ & $5(6.4)$ & $8(9.0)$ & $32(27.8)$ & $<.001$ \\
\hline Infection site & & & & & & & .342 \\
\hline Left-side & $356(87.5)$ & $53(85.5)$ & $54(85.7)$ & $67(85.9)$ & $79(88.8)$ & $103(89.6)$ & \\
\hline Right-side & $31(7.6)$ & $7(11.3)$ & $3(4.8)$ & $8(10.3)$ & $4(4.5)$ & $9(7.8)$ & \\
\hline Left+ Right-side & $20(4.9)$ & $2(3.2)$ & $6(9.5)$ & $3(3.8)$ & $6(6.7)$ & $3(2.6)$ & \\
\hline Infection valve & & & & & & & $>.05$ \\
\hline Single valve & $295(72.5)$ & $38(61.3)$ & $46(73.0)$ & $55(70.5)$ & $58(65.2)$ & $98(85.2)$ & .002 \\
\hline Mitral valve & $134(32.9)$ & $16(25.8)$ & $20(31.7)$ & $24(30.8)$ & $30(33.7)$ & $44(38.3)$ & \\
\hline Aortic valve & $143(35.1)$ & $18(29.0)$ & $23(36.5)$ & $25(32.1)$ & $27(30.3)$ & $50(43.5)$ & \\
\hline Multi-valve, $n(\%)$ & $79(19.4)$ & $13(21.0)$ & $15(23.8)$ & $13(16.7)$ & $24(27.0)$ & $14(12.2)$ & \\
\hline Endocardial or arterial intima & $33(8.1)$ & $11(17.7)$ & $2(3.2)$ & $10(12.8)$ & $7(7.9)$ & $3(2.6)$ & \\
\hline \multicolumn{8}{|l|}{ Type of IE } \\
\hline Native valve IE & $370(90.9)$ & $50(80.6)$ & $58(92.1)$ & $72(92.3)$ & $77(86.5)$ & $113(98.3)$ & .002 \\
\hline Prosthetic valve IE or cardiac device-related IE & $37(9.1)$ & $12(19.3)$ & $5(7.9)$ & $6(7.7)$ & $12(13.5)$ & $2(1.7)$ & .002 \\
\hline \multicolumn{8}{|l|}{ Complications } \\
\hline Embolic events & $125(30.7)$ & $14(22.6)$ & $16(25.4)$ & $16(20.5)$ & $34(38.2)$ & $45(39.1)$ & .003 \\
\hline Cerebral embolism & $74(18.2)$ & $6(9.7)$ & $7(11.1)$ & $12(15.4)$ & $18(20.2)$ & $31(27.0)$ & .001 \\
\hline Heart failure & $215(52.8)$ & $31(50.0)$ & $31(49.2)$ & $43(55.1)$ & $51(57.3)$ & $59(51.3)$ & .661 \\
\hline
\end{tabular}


Table 1 The clinical characteristics of infective endocarditis and changing trends by years from 2007 to 2016 (Continued)

\begin{tabular}{|c|c|c|c|c|c|c|c|}
\hline Variable, $\mathrm{n}(\%)$ & $\begin{array}{l}\text { Total } \\
n=407\end{array}$ & $\begin{array}{l}2007-2008 \\
n=62\end{array}$ & $\begin{array}{l}2009-2010 \\
n=63\end{array}$ & $\begin{array}{l}2011-2012 \\
n=78\end{array}$ & $\begin{array}{l}2013-2014 \\
n=89\end{array}$ & $\begin{array}{l}2015-2016 \\
n=115\end{array}$ & $P$ value \\
\hline Vegetation & $350(86.0)$ & $44(71.0)$ & $54(85.7)$ & $62(79.5)$ & $82(92.1)$ & $108(93.9)$ & $<.001$ \\
\hline Vegetation length & & & & & & & $<.001$ \\
\hline$\leq 10 \mathrm{~mm}$ & $90(22.1)$ & $9(14.5)$ & $12(19.0)$ & $16(20.5)$ & $21(23.6)$ & $32(27.8)$ & \\
\hline$>10 \mathrm{~mm}<20 \mathrm{~mm}$ & $197(48.4)$ & $25(40.3)$ & $31(49.2)$ & $31(39.7)$ & $52(58.4)$ & $58(50.4)$ & \\
\hline$\geq 20 \mathrm{~mm} \leq 30 \mathrm{~mm}$ & $51(12.5)$ & $8(12.9)$ & $10(15.9)$ & $14(17.9)$ & $6(6.7)$ & $13(11.3)$ & \\
\hline$>30 \mathrm{~mm}$ & $12(2.9)$ & $2(3.2)$ & $1(1.6)$ & $1(1.3)$ & $3(3.4)$ & $5(4.3)$ & \\
\hline Valvular perforation & $72(17.8)$ & $3(4.9)$ & $7(11.1)$ & $11(14.3)$ & $21(23.6)$ & $30(26.1)$ & $<.001$ \\
\hline Perivalvular abscess & $30(7.4)$ & 0 & $1(1.6)$ & $3(3.9)$ & $12(13.5)$ & $14(12.2)$ & $<.001$ \\
\hline Positive rate blood culture & $222(54.5)$ & $41(66.1)$ & $33(52.4)$ & $36(46.2)$ & $44(49.4)$ & $68(59.1)$ & .663 \\
\hline Streptococci & $100(24.6)$ & $17(27.4)$ & $9(14.3)$ & $15(19.2)$ & $20(22.5)$ & $39(33.9)$ & $.028^{*}$ \\
\hline Staphylococci & $80(19.7)$ & $14(22.6)$ & $17(27.0)$ & $12(15.4)$ & $15(16.9)$ & $22(19.1)$ & $.668^{*}$ \\
\hline Enterococci & $5(1.2)$ & $1(1.6)$ & $1(1.6)$ & $1(1.3)$ & $1(1.1)$ & $1(0.9)$ & $.051^{*}$ \\
\hline Surgical indications & $403(99.0)$ & $60(96.8)$ & $63(100.0)$ & 76 (97.4) & $89(100.0)$ & $\begin{array}{l}115 \\
(100.0)\end{array}$ & .061 \\
\hline Surgical treatment & $235(57.7)$ & $36(58.1)$ & $34(54.0)$ & $44(56.4)$ & $58(65.2)$ & $63(54.8)$ & .900 \\
\hline In-hospital mortality & $43(10.6)$ & $12(19.4)$ & $3(4.8)$ & $2(2.6)$ & $10(11.2)$ & $16(13.9)$ & .910 \\
\hline One-year mortality & $46(11.3)$ & $13(21.0)$ & $3(4.8)$ & $4(5.1)$ & 10 (11.2.) & $16(13.9)$ & .868 \\
\hline
\end{tabular}

* percentage accouting for the positive results in each group

SD Standard deviation, IQR Interquartile range, IE Infective endocarditis, TEE Transesophageal echocardiography

showed that the incidence of IE has increased in the past decades [4]. Cresti et al. [9] found the incidence was 4.6/ 100,000 person-years with a significant linear increase between 1998 and 2014. Keller et al. [10] found that the incidence of IE in Germany was 11.6/100,000 person- years between 2005 and 2015, and the incidence increased continuously during the study period, especially in the last five years. However, in our study, we found that the incidence of IE was between 0.33 and 0.72 patients per 1000 admissions and the incidence remained

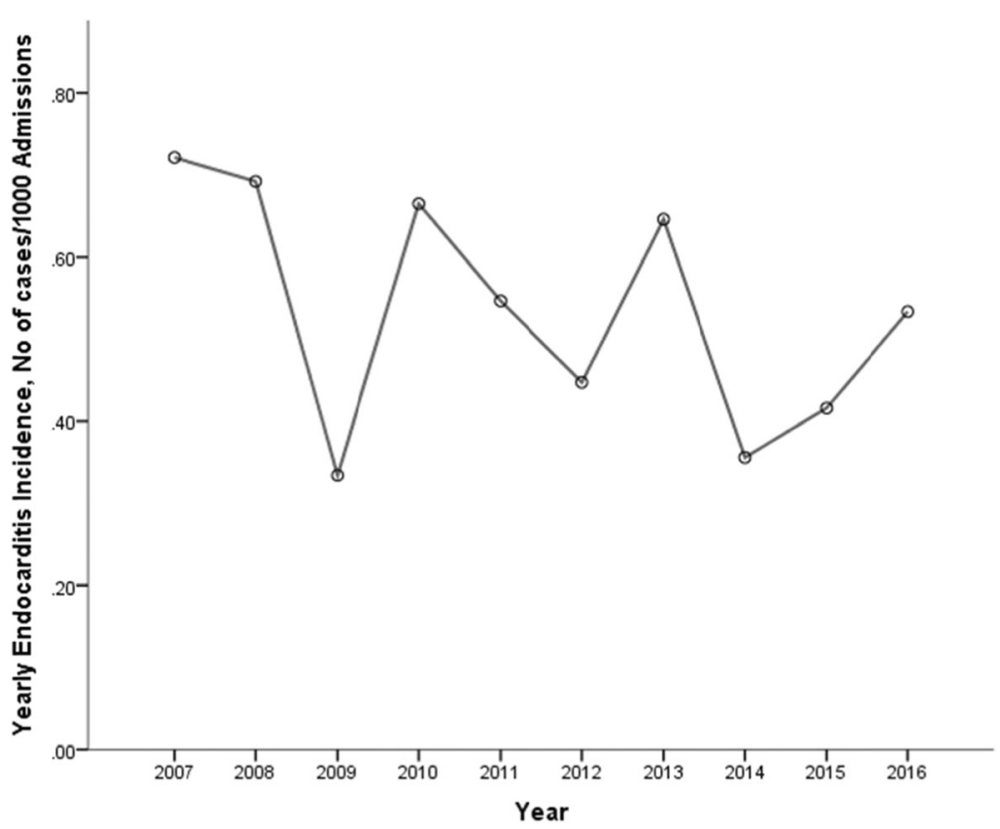

Fig. 1 Incidence of infective endocarditis from 2007 to 2016 in hospitalized patients. The annual incidence of IE were between 0.33 and 0.72 patients per 1000 admissions and the incidence was stable over this period (Linear regression showed $P=0.168$ ) 
Table 2 Risk factors of in-hospital outcome in patients with infective endocarditis (univariate analysis)

\begin{tabular}{|c|c|c|c|}
\hline \multirow[t]{2}{*}{ Variable, n (\%) } & \multicolumn{2}{|c|}{ In-hospital outcome } & \multirow[t]{2}{*}{$P$ value } \\
\hline & $\begin{array}{l}\text { Survival } \\
n=364\end{array}$ & $\begin{array}{l}\text { Death } \\
n=43\end{array}$ & \\
\hline Age,mean \pm SD & $48 \pm 16$ & $53 \pm 16$ & .047 \\
\hline Man & $237(65.1)$ & $25(58.1)$ & .367 \\
\hline Underlying heart disease & $194(53.3)$ & $27(62.8)$ & .237 \\
\hline Rheumatic heart disease & $62(17.0)$ & $7(16.3)$ & .901 \\
\hline Congenital heart disease & $95(26.1)$ & $10(23.3)$ & 687 \\
\hline Previous cardiac surgery & $33(9.1)$ & $11(25.6)$ & .001 \\
\hline Degenerative heart disease & $13(3.6)$ & 0 & .377 \\
\hline Others & $18(4.9)$ & $4(9.3)$ & .273 \\
\hline \multicolumn{4}{|l|}{ Comorbidities } \\
\hline Chronic obstructive pulmonary disease & $5(1.4)$ & $1(2.3)$ & .491 \\
\hline Cancer & $11(3.0)$ & $1(2.3)$ & $>.05$ \\
\hline Hemodialysis & $9(2.5)$ & $5(11.6)$ & .002 \\
\hline Hepatitis $B$ virus infection & $16(4.4)$ & $2(4.7)$ & $>.05$ \\
\hline Liver cirrhosis & $4(1.1)$ & 0 & $>.05$ \\
\hline Hypertension & $68(18.7)$ & $14(32.6)$ & .032 \\
\hline Diabetes mellitus & $32(8.8)$ & $5(11.6)$ & .541 \\
\hline \multicolumn{4}{|l|}{ Complications } \\
\hline Heart failure & $179(49.2)$ & $36(83.7)$ & $<.001$ \\
\hline Intracranial infection & $15(4.1)$ & $2(4.7)$ & 698 \\
\hline Cerebral embolism & $55(15.1)$ & $19(44.2)$ & $<.001$ \\
\hline Cerebral hemorrhage & $16(4.4)$ & $7(16.3)$ & .001 \\
\hline Arrhythmia & $65(17.9)$ & $15(34.9)$ & .008 \\
\hline Hepatic insufficiency & $57(15.7)$ & $15(34.9)$ & .002 \\
\hline Renal insufficiency & $60(16.5)$ & $21(48.8)$ & $<.001$ \\
\hline Pulmonary hypertension & $92(25.6)$ & $24(57.1)$ & $<.001$ \\
\hline Valvular perforation & $64(17.7)$ & $8(18.6)$ & .881 \\
\hline Perivalvular abscess & $26(7.2)$ & $4(9.3)$ & .544 \\
\hline Vegetation length & & & $<.001$ \\
\hline$\leq 10 \mathrm{~mm}$ & $87(23.9)$ & $3(7.0)$ & \\
\hline$>10 \mathrm{~mm}<20 \mathrm{~mm}$ & $177(48.6)$ & $20(46.5)$ & \\
\hline$\geq 20 \mathrm{~mm} \leq 30 \mathrm{~mm}$ & $46(12.6)$ & $5(11.6)$ & \\
\hline$>30 \mathrm{~mm}$ & $4(1.1)$ & $8(18.6)$ & $<.001$ \\
\hline Vegetation extent & $142(39.0)$ & $16(37.2)$ & .819 \\
\hline IE type & & & .004 \\
\hline Native valve IE & 337 (92.6) & $33(76.7)$ & \\
\hline Prosthetic valve IE or cardiac device-related IE & $27(7.4)$ & $10(23.3)$ & .001 \\
\hline Previous antibiotic use & $291(82.4)$ & $30(75.0)$ & .249 \\
\hline Causative organism & & & .049 \\
\hline Streptococci & $95(26.1)$ & $5(11.6)$ & \\
\hline Staphylococci & $69(19.0)$ & $11(25.6)$ & \\
\hline Staphylococcus aureus & $32(8.8)$ & $8(18.6)$ & $<.001$ \\
\hline Pitt score & & & $<.001$ \\
\hline
\end{tabular}


Table 2 Risk factors of in-hospital outcome in patients with infective endocarditis (univariate analysis) (Continued)

\begin{tabular}{|c|c|c|c|}
\hline \multirow[t]{2}{*}{ Variable, n (\%) } & \multicolumn{2}{|c|}{ In-hospital outcome } & \multirow[t]{2}{*}{$P$ value } \\
\hline & $\begin{array}{l}\text { Survival } \\
n=364\end{array}$ & $\begin{array}{l}\text { Death } \\
n=43\end{array}$ & \\
\hline$<4$ & $359(98.6)$ & $23(53.5)$ & \\
\hline$\geq 4$ & $5(1.4)$ & $20(46.5)$ & \\
\hline Surgical treatment & $221(60.7)$ & $14(32.6)$ & $<.001$ \\
\hline
\end{tabular}

SD Standard deviation, IE Infective endocarditis

stable during the period, which was lower in comparison with the developed countries (approximately 1-1.3 patients per 1000 hospital admissions) $[4,9]$.The difference in incidence of IE from different studies may be related to the geographical location of the study, the time period selected, and the difference in diagnostic techniques of different institutions.

In our study, we found that the mean age at the time of IE episodes were younger than those reported from developed countries, although the mean age increased during this period. The proportion of old patients with IE increased gradually in this period, which was more obvious in developed countries [9, 11]. Erichsen et al. [12] found that the incidence increased substantially for elderly IE patients between 1994 and 2011, with the highest incidence rate of 3.38 for patients more than 80 years old at IE onset. In Oliver et al.' s report [13], 49\% of IE patients were over 65 years old and $11.2 \%$ were over 80 years old. The changes in the age of IE onset may owing to the aging population. And as a result of the older onset age, patients with IE in the latter part of the study period were more likely to have comorbidities compared with patients in the earlier part of the study period.

We found that CHD had become the most common underlying heart disease for patients with IE in our study. This result was consistent with other researches from China, where the proportion of CHD IE ranging from $20.1-36.7 \%$ [14-16]. RHD once the most common underlying heart disease in the 1990s according to Chao et al.' s report [17] was gradually decreasing in our study, which was consistent with other researches from China $[6,15,16,18]$. These findings were some different from developed countries [6]. Researches from developed countries presented that DVD, PVE and implantable electronic devices related IE had gradually increased and replaced RHD as the leading heart disease $[1,4,10]$. This difference may contributed to the late diagnosis for $\mathrm{CHD}$, the low screening rate for newborn and the low proportion of surgical treatment when they were young in China [6].

According to Song Bing's report [19], there were $35.6 \%$ patients diagnosed as CHD after 18 years old, and among patients with septal defect, $60.1 \%$ were diagnosed in adulthood, and only $6.7 \%$ were diagnosed in infancy. Data from Guangdong congenital heart defects monitoring network showed that the cumulative incidence of CHD in Guangdong province increased from 3.74 to 11.29 per thousand per year from 2004 to 2016 and the number of adult CHD gradually increased, although it currently accounts for only $21 \%$, but the growth is nearly 18\% [20]. According to Lai Xiaojin's report [20] based on a 2356 cases analysis, the rate of adults with CHD has an increasing trend. The same phenomenon was seen from developed countries. This might due to that the symptoms and signs were not obviously during adolescence for some non-severe $\mathrm{CHD}$, and they failed to be

Table 3 Risk factors of in-hospital outcome in patients with infective endocarditis (multivariate analysis)

\begin{tabular}{|c|c|c|c|}
\hline Variable & $P$ value & OR & $95 \% \mathrm{Cl}$ \\
\hline Male & .413 & & \\
\hline Cerebral embolism & .137 & & \\
\hline Hemodialysis & .041 & 4.697 & $1.068-20.665$ \\
\hline Pulmonary hypertension & .001 & 5.308 & $2.034-13.852$ \\
\hline Causative organism & .544 & & \\
\hline Staphylococcus aureus & .422 & & \\
\hline Pitt score $\geq 4$ & $<.001$ & 28.594 & $5.561-148.173$ \\
\hline Vegetation length $>30 \mathrm{~mm}$ & .011 & 13.754 & $1.832-103.250$ \\
\hline Prosthetic valve IE or cardiac device-related IE & .064 & & \\
\hline Surgical treatment & .325 & & \\
\hline
\end{tabular}

$O R$ odds ratios, $\mathrm{Cl}$ confidence interval 
identified due to the restrictions of local medical and economic conditions in our region.

IE was an important complication for patients with CHD [21, 22]. According to the published reports, the risk of developing into IE increased in patients with CHD [21, 23, 24]. Darren et al. [24] found that the IE risk exceeded 100 times in patients with ACHD compared to that of the general population and 2.5 times that of children with CHD [24, 25]. The proportion of patients with CHD in our study was as high as $25.8 \%$.

TEE was performed in only $12.8 \%$ patients with IE in our study, as most patients diagnosed after TTE did not perform TEE routinely. Compared to the literature published from China on IE, the rate approached to other studies in our region [14-16]. But it was significantly lower than that reported by other studies from developed countries with 74-100\% [26, 27]. However, according to the 2015 European Association of Cardiology guidelines on IE, for TTE positive patients, TEE should be performed to exclude perivalvular complications [1]. The low utilization rate of TEE could directly resulted in the low detection rate of perivalvular complications such as valvular perforation and perivalvular abscess. Besides, this could cause the missed diagnoses of IE in patients with unobvious valvular lesions or with basic valvular lesions. This underlined that we still need to improve the use of TEE in IE diagnoses to reduce missed diagnoses.

The positive rate of blood culture in our study was lower compared with other studies from developed countries, where the rate of positive blood culture varied from 83 to $96 \%[2,10,13,28]$.However, the rate was approximate to other studies from China varied from $38.5-70.1 \%[14,15$, 18]. The low microbiology detection rate could be related to the extensive use of antibiotics before blood culture, and the proportion of patients with prior antibiotics use was as high as $81.7 \%$ in our study. Besides, as a tertiary hospital, most patients in our hospital had been referred from other medical institutions. They usually had a history of antibiotic treatment previous to the blood cultures. What's more, the blood cultures of the HACEK group, serology tests for mycoplasma, bartonella, legionella and the polymerase chain reaction (PCR) were not performed in our hospital. Therefore, we suggested that patients with suspected bloodstream infection should receive blood cultures routinely before the use of antibiotics.

In our study, Streptococci was the main pathogen accounting for $24.6 \%$, followed by Staphylococci accounting for $19.7 \%$, and these were the same as reports in the 1990s from China [17]. This phenomenon was similar to other developing countries $[5,6]$ but was different from developed countries [4]. For IE in developed countries, the proportion of Staphylococci increased gradually and became the main pathogenic bacteria $[4,6]$. The increase in Staphylococcus IE was mainly due to the high incidence of intravenous drug addicts, hemodialysis patients and elderly patients with comorbidities $[3,4,29,30]$. However, in our study, the proportion of patients with intravenous drug addicts, hemodialysis patients and octogenarians was lower compared with developed countries. Besides, most of patients in our study were community origin IE, and Streptococcus IE was the main for community origin IE according to the previous reports [16].

Enterococci IE was less common and the rate was stable in our study. This were consistent with another report from our region [18]. In this report, Enterococci was identified in 5 patients (2.9\%) and the proportion was stable during 2008 to 2015 [18]. However, this was quite different from developed countries [6]. In developed countries, Enterococci IE was more common and was the third leading cause of IE after Staphylococci and Streptococci ranging between 7 and $18 \%[9,10,28]$. According to the previous report, Enterococci IE was most frequently seen in elderly men with a relatively low short-term mortality [31].

According to the published studies, older age, prosthetic valve IE, heart failure, septic shock, Staphylococcus aureus, and large vegetation were predictors of poor outcome in patients with IE [1, 4]. In our study, we found that hemodialysis, pulmonary hypertension, Pitt score $\geq 4$ and vegetation length $>30 \mathrm{~mm}$ were independent risk factors for in-hospital mortality. The risk of in-hospital mortality in patients with hemodialysis increased by 4.697 times and in patients with pulmonary hypertension, the risk of inhospital mortality increased by 5.308 times.

There are several limitations in our study. First, as a retrospective study, there exists information bias, and we are unable to obtain information on the patient exposure to dental procedures and the use of antibiotic prophylaxis. Second, the study used a single-center cohort in a tertiary teaching hospital with possible selection bias that could not represent the entire Chinese condition. Finally, as a nonrandomised study, there were associated limitations and selection bias affecting comparisons between the inhospital outcomes. Therefore, we suggest multiple-center prospective cohort studies performed in our region.

\section{Conclusions}

In conclusion, this study is currently a large sample research in IE from our region. It presents that the mean age of IE onset has being older, congenital heart disease is the predominant cardiac disease and Streptococci is still the predominant pathogen. Attention should be paid to the management of congenital heart disease especially among adult with congenital heart disease. Besides, it shows that patients with hemodialysis, pulmonary hypertension, Pitt score $\geq 4$ and vegetation length $>30 \mathrm{~mm}$ have an worse in-hospital outcome. Our findings will have an important impact in the improvement both in the diagnosis and treatment of IE in our region in the future. 


\section{Abbreviations}

IE: Infective endocarditis; PVE: Prosthetic valve endocarditis; RHD: Rheumatic heart disease; CHD: Congenital heart disease; ESC: European Society of Cardiology; TTE: Transthoracic echocardiography; TEE: Transesophageal echocardiography; SD: Standard deviation; IQR: Interquartile range; OR: Odds ratios; HR: Hazard ratio; $\mathrm{Cl}$ : Confidence interval

\section{Acknowledgements}

We are very grateful to the staffs in the Medical Record Room in the First Affiliated Hospital of Zhejiang University for their support and assistance.

\section{Authors' contributions}

ZZW designed the study and created study protocols, ZZW and YC performed the data collection, data analysis and drafts the manuscript. YHX supervised the study development, helped to review the manuscript and made critical revision to the paper. TTX TSN and QYS performed data collection and helped to review the manuscript. All authors read and approved the final manuscript.

\section{Funding}

This work was partially supported by grants from the Key Research and Development Program of Zhejiang Province (No.2015C03032). The funder was not involved in the design of the study, data collection, analysis and interpretation of the data and in writing the manuscript.

\section{Availability of data and materials}

The datasets used and analyzed during the current study are available from the corresponding author on reasonable request.

\section{Ethics approval and consent to participate}

Ethics approval for this study was submitted and approved through Research Ethics Committee of the First Affiliated Hospital, College of Medicine, Zhejiang University. The consent to participate was waived by our institutional review board since this study was retrospective data collection. The patient information used in this study was anonymised before its use.

\section{Consent for publication}

Not applicable.

\section{Competing interests}

The authors declare that they have no competing interests.

\section{Author details}

'State Key Laboratory for Diagnosis and Treatment of Infectious Diseases, National Clinical Research Center for Infectious Diseases,Collaborative Innovation Center for Diagnosis and Treatment of Infectious Diseases, the First Affiliated Hospital, College of Medicine, Zhejiang University, 79 Qingchun Road, Hangzhou, Zhejiang Province, China. ${ }^{2}$ The Second Affiliated Hospital and Yuying Children' Hospital of Wenzhou Medical University, Wenzhou, China.

\section{Received: 25 February 2020 Accepted: 12 June 2020}

\section{Published online: 18 June 2020}

\section{References}

1. Linhartova K, Benes J, Gregor P. 2015 ESC guidelines for the management of infective endocarditis. Summary document prepared by the Czech Society of Cardiology. Cor Et Vasa. 2016;58(1):E107-E28.

2. Toyoda N, Chikwe J, Itagaki S, Gelijns AC, Adams DH, Egorova NN. Trends in infective endocarditis in California and New York state, 1998-2013. JAMA 2017;317(16):1652-60.

3. Cahill TJ, Baddour LM, Habib G, Hoen B, Salaun E, Pettersson GB, Schafers $\mathrm{HJ}$, Prendergast BD. Challenges in infective endocarditis. J Am Coll Cardiol. 2017:69(3):325-44

4. Ambrosioni J, Hernandez-Meneses M, Tellez A, Pericas J, Falces C, Tolosana JM, Vidal B, Almela M, Quintana E, Llopis J, et al. The Changing Epidemiology of Infective Endocarditis in the Twenty-First Century. Curr Infect Dis Rep. 2017:19(5):21.

5. Elbey MA, Kalkan ME, Kaya MG, Bulur S, Ulus T, Elbey HK. A multicenter study on experience of 13 tertiary hospitals in Turkey in patients with infective endocarditis. Anadolu Kardiyol Derg. 2013;13(6):523-7.
6. Njuguna B, Gardner A, Karwa R, Delahaye F. Infective endocarditis in lowand middle-income countries. Cardiol Clin. 2017:35(1):153-63.

7. Habib G, Lancellotti P, Antunes MJ, Bongiorni MG, Casalta JP, Del Zotti F, Dulgheru R, El Khoury G, Erba PA, lung B, et al. 2015 ESC guidelines for the management of infective endocarditis. Kardiol Pol. 2015;73(11):963-1027.

8. Mahmood SS, Wang TJ. The epidemiology of congestive heart failure: the Framingham heart study perspective. Glob Heart. 2013;8(1):77-82.

9. Cresti A, Chiavarelli M, Scalese M, Nencioni C, Valentini S, Guerrini F, D'Aiello I, Picchi A, De Sensi F, Habib G. Epidemiological and mortality trends in infective endocarditis, a 17-year population-based prospective study. Cardiovasc Diagn Ther. 2017;7(1):27-35.

10. Keller K, von Bardeleben RS, Ostad MA, Hobohm L, Munzel T, Konstantinides S, Lankeit M. Temporal trends in the prevalence of infective endocarditis in Germany between 2005 and 2014. Am J Cardiol. 2017;119(2):317-22.

11. Cecchi E, Chirillo F, Castiglione A, Faggiano P, Cecconi M, Moreo A, Cialfi A, Rinaldi M, Del Ponte S, Squeri A, et al. Clinical epidemiology in Italian registry of infective endocarditis (RIEI): focus on age, intravascular devices and enterococci. Int J Cardiol. 2015;190:151-6.

12. Erichsen $\mathrm{P}$, Gislason $\mathrm{GH}$, Bruun NE. The increasing incidence of infective endocarditis in Denmark, 1994-2011. Eur J Intern Med. 2016;35:95-9.

13. Oliver L, Lavoute C, Giorgi R, Salaun E, Hubert S, Casalta JP, Gouriet F, Renard S, Saby L, Avierinos JF, et al. Infective endocarditis in octogenarians. Heart. 2017:103(20):1602-9.

14. Wei XB, Liu YH, Huang JL, Chen XL, Yu DQ, Tan N, Chen JY, He PC. Prediabetes and diabetes are both risk factors for adverse outcomes in infective endocarditis. Diabet Med. 2018;35(11):1499-507.

15. Zhu W, Zhang Q, Zhang JP. The changing epidemiology and clinical features of infective endocarditis: a retrospective study of 196 episodes in a teaching hospital in China. BMC Cardiovasc Disord. 2017;17(1):113.

16. Yang FF, Zhang BY, Yu J, Shao LY, Zhou P, Zhu LP, Chen S, Zhang WH, Weng $\mathrm{XH}$, Zhang JM, et al. Epidemiology and the prognosis of healthcareassociated infective endocarditis in China: the significance of nonnosocomial acquisition. Emerg Microbes Infect. 2015;4(7):e38.

17. Chao TH, Li YH, Tsai WC, Tsai LM, Lin LJ, Chen JH, Yang YJ. Prognostic determinants of infective endocarditis in the 1990s. J Formos Med Assoc. 1999;98(7):474-9.

18. Xu H, Cai S, Dai H. Characteristics of Infective Endocarditis in a Tertiary Hospital in East China. PLoS One. 2016:11(11):e0166764.

19. Song B, Gao X, Liu RS, Xue HL, Chen DW, Li ZL, Zhao HL. Epidemiological analysis of hospitalized patients with congenital heart disease in the first Hospital of Lanzhou University from 2011 to 2015. Chinese Journal of Reproductive Health. 2018;29(01):21-4.

20. Lan XJ, Li SS, Wei LZ, Liang Y, Liao MS, Song ZQ, Zhou XW, Zhang X, Liu BY, Wen ZL. Epidemiological analysis of the composition ratio of 2356 cases of congenital heart disease. Med J National Defending Forces Southwest China. 2002;04:298-301.

21. Diller GP, Baumgartner $\mathrm{H}$. Endocarditis in adults with congenital heart disease: new answers-new questions. Eur Heart J. 2017:38(26):2057-9.

22. Soufi A, Veyrier M, Ducreux C, Sassolas F, Henaine R, Metton O, Ninet J, Joly $\mathrm{H}$, Bozio A, Di Filippo S. Infective endocarditis in adults with congenital heart disease. Arch Cardiovasc Dis. 2013;106(8-9):477.

23. Moore B, Cao J, Kotchetkova I, Celermajer DS. Incidence, predictors and outcomes of infective endocarditis in a contemporary adult congenital heart disease population. Int J Cardiol. 2017:249:161-5.

24. Mylotte D, Rushani D, Therrien J, Guo L, Liu A, Guo K, Martucci G, Mackie AS, Kaufman JS, Marelli A. Incidence, predictors, and mortality of infective endocarditis in adults with congenital heart disease without prosthetic valves. Am J Cardiol. 2017;120(12):2278-83.

25. R Rushani D, Kaufman JS, lonescu-Ittu R, Mackie AS, Pilote L, Therrien J, Marelli AJ: Infective endocarditis in children with congenital heart disease: cumulative incidence and predictors. Circulation. 2013;128(13):1412-1419.

26. van den Brink F, Hasenaar J, Winia V, Klomp M, Van Vlies B, Nicastia D, Groenmeijer B, Braam R, Jaarsma W, Kupper AJF. Prognostic factors in infective endocarditis in general hospitals in the Netherlands. Neth Heart J. 2016:24(12):717-21.

27. Lamas CC, Fournier PE, Zappa M, Brandao TJD, Januario-da-Silva CA, Correia MG, Barbosa GIF, Golebiovski WF, Weksler C, Lepidi H, et al. Diagnosis of blood culture-negative endocarditis and clinical comparison between blood culturenegative and blood culture-positive cases, Infection. 2016:44(4):459-66.

28. Fernandes E, Olive C, Inamo J, Roques F, Cabie A, Hochedez P. Infective endocarditis in French West Indies: a 13-year observational study. Am J Trop Med Hyg. 2017;97(1):77-83. 
29. Buchi AE, Hoffmann M, Zbinden S, Sendi P. Infective endocarditis: how do we currently interpret the Duke minor criterion "predisposing heart condition" in native valves? Cardiol Ther. 2017;6(1):121-8.

30. Cahill TJ, Prendergast BD. Infective endocarditis. Lancet. 2016;387(10021): 882-93.

31. McDonald JR, Olaison L, Anderson DJ, Hoen B, Miro JM, Eykyn S, Abrutyn E, Fowler VG, Habib G, Selton-Suty C, et al. Enterococcal endocarditis: 107 cases from the international collaboration on endocarditis merged database. Am J Med. 2005;118(7):759-66.

\section{Publisher's Note}

Springer Nature remains neutral with regard to jurisdictional claims in published maps and institutional affiliations.

Ready to submit your research? Choose BMC and benefit from:

- fast, convenient online submission

- thorough peer review by experienced researchers in your field

- rapid publication on acceptance

- support for research data, including large and complex data types

- gold Open Access which fosters wider collaboration and increased citations

- maximum visibility for your research: over $100 \mathrm{M}$ website views per year

At BMC, research is always in progress.

Learn more biomedcentral.com/submissions 